\title{
GIUH-Nash based runoff prediction for Debarwa catchment in Eritrea
}

\author{
Anghesom Gehbrehiwot ${ }^{*}$ and Dmitry Kozlov \\ Moscow State University of Civil Engineering, Yaroslavskoe shosse, 26, Moscow, 129337, Russia
}

\begin{abstract}
Correct assessment of river flow is necessary to resolve a wide range of problems in the management and use of water resources. Recently, research towards the use of geomorphologic instantaneous unit hydrograph (GIUH) coupled with other conceptual models approach for flood prediction from ungauged catchments has been intensified. Widespread accessibility to geographic information system and remotely sensed imagery which are powerful tools for acquiring model inputs is one possible reason. This study, therefore, aims at direct surface runoff (DSRO) prediction using the geomorphologic instantaneous unit hydrograph based Nash model (GIUH-Nash) from ungauged catchment. DEM obtained from Shuttle Radar Topography Mission (SRTM) having $30 \mathrm{~m}$ resolution is used to generate the catchment's physiographic and geomorphologic characteristics with the help of quantum geographic information system (QGIS). Based on this information, the GIUH-Nash model is used to simulate DSRO for different storm events. A visual comparison of observed values to predicted values of the runoff hydrographs as well as statistical indices shows that DSRO could be predicted with reasonable accuracy provided complete understanding of the model development and it's evaluation procedures are properly followed. In respect of this, some key aspects that affect the performance of the model have been suggested.
\end{abstract}

\section{Introduction}

The correct assessment of river flow is necessary to resolve a wide range of problems in the management and use of water resources, which are currently being solved using various types of modelling. In most practical problems, the commonly used method of flood prediction using the unit hydrograph (UH) theory introduced by Sherman 1 cannot be implemented, because it requires recorded rainfall and runoff data. Under these circumstances, design and development of water resources projects remain to be the main challenge in spite of intensive efforts put in to resolve the same by numerous hydrologists, most notably through systems approach.

A catchment acts as a hydrological system transforming input hydrograph into a flood hydrograph. The transfer function contains a mathematical characterization of the process that relates the inputs and outputs. Based on this system transformation approach, numerous

\footnotetext{
*Correspnding author: bahghi2012@gmail.com
} 
conceptual rainfall-runoff models have been developed to simulate the rainfall-runoff process of transformation [2]. Nash 3 proposed a conceptual model consist of a cascade of linear reservoirs. However, many literatures argued on the success of these models due to non-linear relationship between rainfall and runoff, for example, 4 and the limitation of historical input-output data for the determination of parameters.

Analytic and trial-and-error methods are some of the currently employed techniques to estimate synthetic unit hydrograph for ungauged catchments. In this regard, the technique of regionalization of parameters utilizing the data from the gauged catchments in hydrometeorologically homogenous regions can be applied. But, the process of regionalization is a difficult task the fact that it requires not only a good amount of rainfall-runoff data for gauged catchments but also hydro-meteorological homogeneity of regions is difficult to ascertain. Moreover, intermittent update of model parameters that include the effects of land-use and climate patterns is required. The difficulty arising from the dependence of the $\mathrm{UH}$ on the duration of the effective rainfall is avoided by letting the duration be diminished indefinitely so as to produce instantaneous unit hydrograph (IUH).

Geomorphology based models has become one of the most widely researched areas in surface water hydrology for the computation of runoff hydrographs for completely ungauged or partially gauged catchments. Since Rodriguez-Iturbe and Valdes [5] presented the geomorphologic instantaneous unit hydrograph (GIUH), there have been many attempts to obtain IUH that incorporates the geomorphologic properties of the catchment 6-8. The basis for GIUH development was the intensive use of stream order laws proposed by Horton 9. The assessment of the IUH for a given catchment allows the user to use this hydrograph for any case of precipitation in the catchment and therefore to assess the response of a given catchment. The comparison of the accuracy and reliability of different methods of UH estimation 10 showed that Nash model is more successful in the estimation of maximum flow, time peak and the overall shapes of the direct runoff hydrographs. GIUH method is still widely used as a tool for predicting flood discharges in ungauged catchments for two main reasons 1: it can be used in situations where there is insufficient amount of input information and is simple for practical application.

The performance of hydrologic models is not the same when applied to different regions due to various factors: topographical, geological and the spatio-temporal variations of climate are some among others. Various literatures indicate that a particular model performs better in the region where it had been developed. In light of this fact and the background information, this study is intended to apply the GIUH-Nash model to predict DSRO from hilly catchment with rugged topography, large overland and stream slopes in Eritrea where there is no information on the past and current unique hydrological models that suit the region for appropriate river flow predictions.

\section{Methods}

\subsection{Study area}

The Upper-Mereb basin with its outlet near the town of Debarwa is located in the southern region, administrative subzone of Debarwa, Eritrea. The catchment outlet is specifically located at $15^{\circ} 05^{\prime} 49^{\prime \prime} \mathrm{N}$ latitude and $38^{\circ} 50^{\prime} 11^{\prime \prime} \mathrm{E}$ longitude about $29 \mathrm{~km}$ South of the capital in the Eastern part of the Mereb-Gash basin (Fig. 1a). The drainage area is estimated to be $200 \mathrm{~km}^{2}$ with its elevation varying between $2550 \mathrm{~m}$ to $1905 \mathrm{~m}$ above mean sea level. The watershed comprises of hilly and dissected mountains mainly covered with open and sparse shrubs and mild slope agricultural lands. Figure $1 \mathrm{~b}$ shows the drainage network and rainfall and flow stations in the area. As per the information obtained from the SRTM - 
DEM processed and analysed using QGIS, average basin slope is $13.325 \%$. The main channel is $37 \mathrm{~km}$ long with a longitudinal slope of $1.16 \%$. Drainage density and channel segment frequency are $0.64 \mathrm{~km} / \mathrm{km}^{2}$ and 0.21 streams per $\mathrm{km}^{2}$, respectively. According to the agro-ecological classification of Eritrea, the Debarwa catchment lies in moist highlands zone where temperature varies from $0^{\circ} \mathrm{C}$ to $32^{\circ} \mathrm{C}$ and an average annual rainfall of $547 \mathrm{~mm}$. Climate in the catchment can be characterized as moderate with December-January being the coldest and March-April the hottest. Maximum precipitation occurs in the summer season, specifically in the months of July and August with a monthly mean rainfall of 185 $\mathrm{mm}$ and $175 \mathrm{~mm}$, respectively.

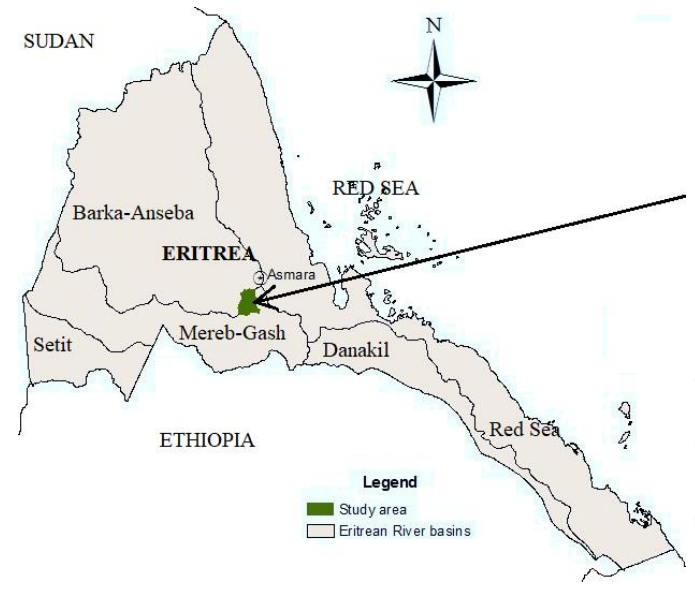

a

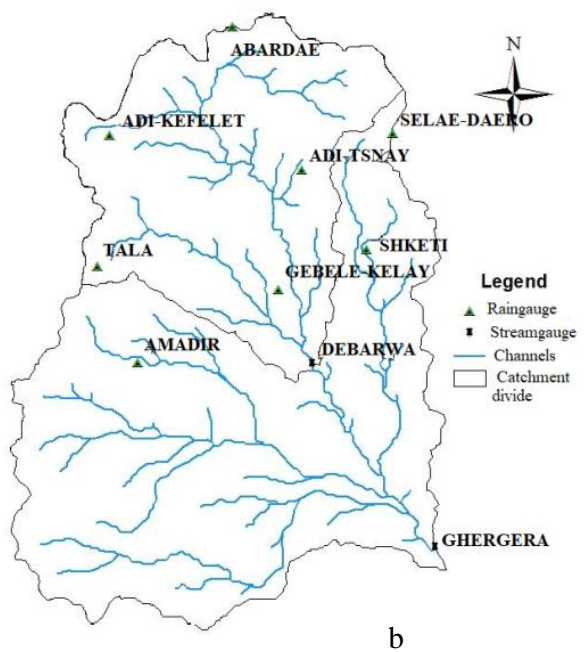

b

Fig. 1. Location map of Eritrea and Upper-Mereb catchment: (a) major basins; Setit, Mereb-Gash, Barka-Anseba, Danakil and Rea Sea, (b) stream network, rainfall stations, stream gauging stations and sub-catchment Debarwa.

\subsection{Nash model}

One of the well-known and widely used models is Nash cascade 3, which can be visualized as a sequence of $n$ linear reservoirs in series, each of which has a lag time $K$, during which individual precipitation is instantly superimposed on the upper reservoir. An input of instantaneous unit effective rainfall over the catchment is applied to the first reservoir instantaneously. The routed outflow from the first reservoir becomes the input to the second reservoir in series and the second reservoir output becomes the input to the third, and so on. Output from the last $n^{\text {th }}$ reservoir is the output from the system representing an IUH for the catchment. The resulting mathematical form for the IUH, $q(t)$ is equivalent to the gamma distribution:

$$
q(t)=\frac{1}{\Gamma(n)} \frac{1}{K}\left(\frac{t}{K}\right)^{n-1} e^{-t / K}
$$

where $\Gamma(n)$ - gamma function; and $K$ - storage coefficient in h.

The parameters $n$ and $K$ can be determined by a number of ways; the most widely used being the method of moments. Mathematically, $n$ may take fractional values to give a wider range of shapes in fitting the observed data. Direct determination of the above 
parameters requires reliable historical records of rainfall-runoff. Under these circumstances, it is necessary to couple the IUH generating methods with other models, such as GIUH.

\subsection{GIUH model}

The relationship between the peak discharge and time peak of the IUH as a function of the geomorphologic characteristics of the catchment 5 is given as follows,

$$
q_{p}=1.31 R_{L}^{0.43}\left(V / L_{\Omega}\right)
$$

and

$$
t_{p}=0.44\left(\frac{L_{\Omega}}{V}\right)\left(\frac{R_{B}}{R_{A}}\right)^{0.55} R_{L}^{-0.38}
$$

where $\Omega$ - stream order of the catchment; $L_{\Omega}$ - length of the highest order stream $(\mathrm{km})$; and $V$ - dynamic velocity parameter (ms-1). The parameters $q_{p}$ and $t_{p}$ have units of time $\left(\mathrm{h}^{-1}\right)$ and $(\mathrm{h})$, respectively.

The bifurcation ratios, length ratios and area ratios were calculated according to Horton's laws based on the following relationships: law of stream numbers $R_{B}=N_{\omega} / N_{\omega+1}$; law of stream lengths; $R_{L}=\bar{L}_{\omega} / \bar{L}_{\omega-1}$; and law of stream areas $R_{A}=\bar{A}_{\omega} / \bar{A}_{\omega-1}$ where $N_{\omega}$ the number of streams, $\bar{L}_{\omega}$ - the mean length of streams and $\bar{A}_{\omega}$ - the mean area of the basins of order $\omega . R_{B}, R_{L}$ and $R_{A}$ represent bifurcation ratio, length ratio and area ratio whose values in nature are normally between 3 and 5 for $R_{B}$, between 1.5 and 3.5 for $R_{L}$ and between 3 and 6 for $R_{A}$, respectively.

Multiplication of equations (2) and (3) that have units of time gives a non-dimensional term which is independent of the dynamic velocity and storm characteristics. It is purely a function of the geomorphologic characteristics:

$$
q_{t} \times t_{p}=0.5764\left(R_{B} / R_{A}\right)^{0.55} R_{L}^{0.05}
$$

The first derivative of (1) gives the time to peak as follows,

$$
t_{p}=(n-1) \times K
$$

Substituting this value for $t_{p}$ in (1), the peak discharge $q_{p}$ of the IUH is obtained as,

$$
q_{p}=\frac{(n-1)^{n-1}}{K \times \Gamma(n)} \times e^{-(n-1)}
$$

The product of (5) and (6) gives a function of the Nash parameter, $n$. Thus,

$$
q_{p} \times t_{p}=\frac{(n-1)^{n}}{\Gamma(n)} \times e^{-(n-1)}
$$

Equating (4) and (7), the following relationship is arrived at.

$$
\frac{(n-1)^{n}}{\Gamma(n)} \times e^{-(n-1)}=0.5764\left(\frac{R_{B}}{R_{A}}\right)^{0.55} R_{L}^{0.05}
$$


The value of $n$ in equation (8) can be solved by Newton-Rapson iteration or Matlab optimization tool. Re-arranging (5) and substituting the right hand side of (3) for $t_{p}$, the value of could be solved from,

$$
K=\frac{0.44}{n-1} \times\left(\frac{L_{\Omega}}{V}\right)\left(\frac{R_{B}}{R_{A}}\right)^{0.55} R_{L}^{-0.38}
$$

The dynamic velocity proposed is the velocity corresponding to the peak runoff for a given rainfall-runoff event in the catchment. This velocity can be obtained with the help of Manning's equation.

$$
V=\frac{1}{n_{m}} R^{2 / 3} S_{m}^{1 / 2}
$$

where $n_{m}$ - Manning roughness coefficient; $R$ - hydraulic radius; and $S_{m}$-slope.

Considering the boundary conditions of the outlet at Debarwa and performing trial and error to obtain optimal prediction of the desired hydrograph, the value of $n_{m}$ is taken to be 0.022. The slope of the main channel $\left(S_{m}\right)$ is computed using the " $85-10$ " slope factor method and is equal to $1.16 \%$.

\subsection{DSRO computation}

The ultimate objective of GIUH development is to derive a UH of required duration which in turn can be used for computation of DSRO. Thus, equation (11) is applied for this purpose. Various literatures recommend the use of a period longer than a quarter of the UH time peak may result in large errors, especially at the hydrograph peak. Accordingly, since the time peak in most of the derived UH from the observed stream flows was one hour, 0.25 $\mathrm{h}$ UH duration is used. The relationship between IUH $[u(t)]$ and D-hour UH $[U(D, t)]$, both of the same unit depth, are related by the formula:

$$
U(D, t)=\frac{1}{D} \int_{t-D}^{t} u(t) d t
$$

where $\mathrm{D}$ - is the duration of the UH.

Five storm events and their corresponding river stages that were recorded in 2006 from stations within the catchment and nearby areas resulting in single-peaked hydrographs were selected for calibration of the GIUH-Nash model. The predicted DSRO hydrographs were estimated by convoluting the effective rainfall hyetograph with the UH obtained from equation (11) for all storm events. Finally, the predicted DSRO were compared to the observed hydrographs through the applications of various goodness of fit functions. Brief discussions of these functions are presented in the ensuing sub-section.

\subsection{Model evaluation}

Since all models and their parameters are approximations to reality, there is a general need for checking with observed data. To compare the performance of the model in DSRO prediction, several statistical indices are employed for judging the fit of calculated to observed hydrograph. These include; the differences between peak magnitudes, a measure of overall fit such as the sum of absolute values or squares of the differences of individual 
ordinates, or differences between lags or other time measures. Moreover, visual inspection of the shape and major characteristics of the hydrographs; time peak, peak discharge, and time base for different storm events are applied. A brief discussion of these methods is presented in the ensuing paragraphs.

The efficiency of a hydrological model is measured by the Nash-Sutcliffe efficiency (NSE), which determines the relative magnitude of the residual variance compared to the measured data variance [11]. It indicates how well the plot of observed versus simulated data fits the 1:1 line and is given by:

$$
N S E=1-\frac{\sum_{t=1}^{N}\left[Q_{o}(t)-Q_{p}(t)\right]^{2}}{\sum_{t=1}^{N}\left[Q_{o}(t)-\bar{Q}_{o}(t)\right]^{2}}
$$

Nash-Sutcliffe efficiency can range from $-\infty$ to 1 . NSE equal to 1 corresponds to a perfect match of modeled discharge to the observed data, NSE equal to 0 indicates that the model predictions are as accurate as the mean of the observed data, whereas an efficiency less than zero $(N S E<0)$ occurs when the observed mean is a better predictor than the model or, in other words, when the residual variance (described by the numerator in the expression above), is larger than the data variance (described by the denominator). Essentially, the closer the model efficiency is to 1, the more accurate the model is.

Special correlation coefficient $(S C)$ which is another goodness of fit between observed and predicted is also given by:

$$
S C=\left\{\frac{2 \sum_{t=1}^{N} Q_{o}(t) \times Q_{p}(t)-\sum_{t=1}^{N}\left[Q_{p}(t)\right]^{2}}{\sum_{t=1}^{N}\left[Q_{o}(t)\right]^{2}}\right\}^{1 / 2}
$$

Mean absolute error $(M A E)$ and root mean square error (RMSE) statistical indices allow us to estimate how the observed and predicted values may differ from the average, which helps in the analysis of the results. The RMSE value is important for determining the plausibility of the phenomenon under study in comparison with the predicted value of the model: if the average value of measurements is very different from the predicted values of the model (a large value of the standard deviation), then the values obtained or the method of obtaining them should be rechecked. The values 0 indicate a perfect match between the model and nature. The $M A E$ and $R M S E$ values can be calculated from equations (14) and (15), respectively:

$$
\begin{aligned}
& M A E=\frac{\sum_{t=1}^{N}\left|Q_{o}(t)-Q_{p}(t)\right|}{N} \\
& R M S E=\left(\frac{\sum_{t=1}^{N}\left[Q_{o}(t)-Q_{p}(t)\right]^{2}}{N}\right)^{1 / 2}
\end{aligned}
$$


where $Q_{o}(t), \overline{Q_{o}}(t)$ and $Q_{p}(t)=$ observed, mean observed and predicted direct runoff rates at time, $t$, respectively; and $N=$ total number of ordinates of direct runoff hydrograph (DRH).

Indices of simulation of single-event allow us estimation of the accuracy of predicted hydrograph ordinates. For this purpose, we used three methods: error of the direct runoff volume $(E V)$, the relative error at the peak $(R E P)$ and the uncertainty of the time occurrence of peak $(E T P)$.

$$
\begin{array}{r}
E V=\left\lfloor\left(V_{o}-V_{p}\right) / V_{o}\right\rfloor \times 100 \\
R E P=\left\lfloor\left(Q_{o}-Q_{p}\right) / Q_{o}\right\rfloor \times 100 \\
E T P=T_{p}-T_{o}
\end{array}
$$

where $V_{o}$ and $V_{p}$ - observed and predicted runoff volumes; $Q_{o}$ and $Q_{p}$ - observed and predicted peak runoff volumes; and $T_{o}$ and $T_{p}$ - time peak of observed and predicted runoffs, respectively.

\section{Results and discussions}

The 3D model of the study area (Fig. 2a) shows the rugged nature of the topography of the area and it's $4^{\text {th }}$ order drainage network. Through on-screen digitization processes, areas corresponding to the $i^{\text {th }}$ stream order were identified. Table 1 provides the details of stream numbers, length, average length and areas for streams of various orders for the study area. The geomorphological parameters namely $R_{B}, R_{L}$ and $R_{A}$ (Figure 2b) were determined graphically by plotting stream order versus log-transformed stream numbers $\left(N_{s}\right)$, mean stream length $\left(L_{m}\right)$ and mean stream area $\left(A_{m}\right)$. The slopes of these lines give the values of the stream ratios. The length of the $4^{\text {th }}$ order, $L_{\Omega}$ is measured as $18.368 \mathrm{~km}$. Accordingly, the Nash parameters were calculated from equations (8) and (9), respectively. The results of the parameters, dynamic velocity, peak runoff and time peak of observed and predicted hydrographs for the different storm events are presented in Table 2. The value of $n$ remains constant the fact that it is a function of the stream ratios whose values don't change for a given drainage network with time contrary to that of time lag, $K$ that changes with respect to time due to dynamic velocity fluctuations.

The dependence of IUH on velocity has serious implications in the estimation of the peak flow and time peak of storms when using the UH approach [5]. This fact was also clearly noticed in the DSRO prediction as a result of the dynamic velocity, which was extremely sensitive to small changes in the Manning's coefficient, $n_{m}$. Besides, the stream ratios' values were within the recommended ranges proposed by Rodriguez [5] for natural catchments. Due to the linear relationship between the stream order and the log-transformed $N_{s}, L_{m}$ and $A m$, good correlations among them probably lead to the success of the GIUHNash model and vice versa. In this case, the coefficient of determination $\left(R^{2}\right)$ that provides an estimate of the strength of the relationship between model and the response variable, were found to be close to 1 (Fig. 2b). The computed dynamic velocities of the different storm events (Table 2) lie in the range of $5.731 \mathrm{~ms}^{-1}$ to $8.333 \mathrm{~ms}^{-1}$. The values seem to be high mainly due to large main channel slope and small value of Manning's coefficient, $n_{m}$. $K$ corresponding to the selected storm events lie in the range of $0.320 \mathrm{~h}$ to $0.466 \mathrm{~h}$ indicating lower storage capacity of the catchment. 
Table 1. Geomorphologic characteristics of Debarwa.

\begin{tabular}{|c|c|c|c|c|c|c|c|}
\hline $\begin{array}{c}\text { Stream } \\
\text { order } \\
(\omega)\end{array}$ & $\begin{array}{c}\text { Stream } \\
\text { numbers } \\
\left(N_{s}\right)\end{array}$ & $\begin{array}{c}\text { Stream } \\
\text { length } \\
L(\mathrm{~km})\end{array}$ & $\begin{array}{c}\text { Mean stream } \\
\text { length } \\
L_{m}(\mathrm{~km})\end{array}$ & $\begin{array}{c}\text { Mean } \\
\text { stream area } \\
A_{m}\left(\mathrm{~km}^{2}\right)\end{array}$ & $R_{B}$ & $R_{L}$ & $R_{A}$ \\
\hline 1 & 40 & 68.252 & 1.706 & 3.104 & & & \\
\hline 2 & 12 & 37.765 & 3.147 & 13.514 & \multirow{2}{*}{3.474} & \multirow{2}{*}{2.183} & \multirow{2}{*}{4.039} \\
\hline 3 & 3 & 18.571 & 6.190 & 58.851 & & \\
\hline 4 & 1 & 18.368 & 18.368 & 199.453 & & \\
\hline
\end{tabular}

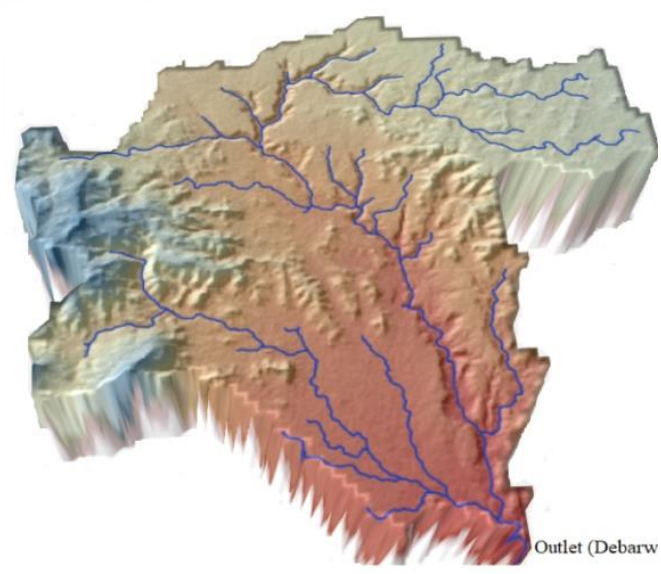

a

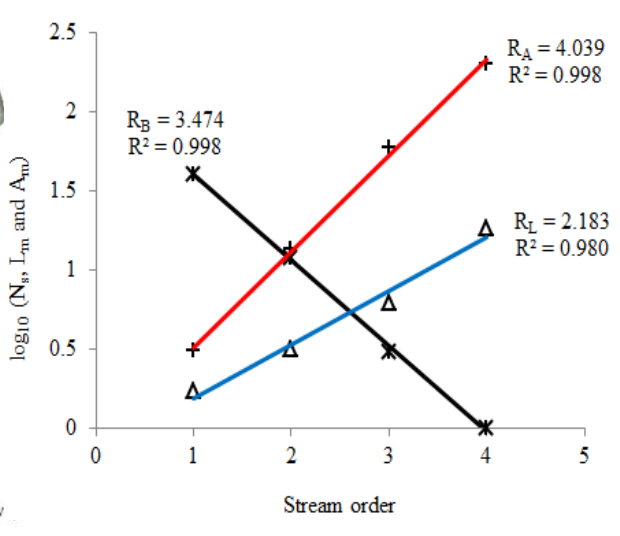

b

Fig. 2. 3D-model of the Debarwa catchment and graphical determination of stream ratios: (a) topography, stream networks and outlet, (b) bifurcation, stream length and stream area ratios.

Table 2. Nash parameters, peak runoff and time peak for selected storm events.

\begin{tabular}{|c|c|c|c|c|c|c|c|}
\hline \multirow{2}{*}{ Storm event } & \multicolumn{2}{|c|}{ Nash parameters } & \multirow{2}{*}{ Velocity } & \multicolumn{2}{c|}{ Peak runoff } & \multicolumn{2}{c|}{ Time peak } \\
\cline { 2 - 3 } \cline { 6 - 8 } & $n$ & $K(\mathrm{~h})$ & $V\left(\mathrm{~ms}^{-1}\right)$ & $\begin{array}{c}\text { Observed } \\
\left(\mathrm{m}^{3} \mathrm{~s}^{-1}\right)\end{array}$ & $\begin{array}{c}\text { Predicted } \\
\left(\mathrm{m}^{3} \mathrm{~s}^{-1}\right)\end{array}$ & $\begin{array}{c}\text { Observed } \\
(\mathrm{h})\end{array}$ & $\begin{array}{c}\text { Predicted } \\
(\mathrm{h})\end{array}$ \\
\hline Jul. 17, 2006 & 3.071 & 0.414 & 6.445 & 62.137 & 62.827 & 0.50 & 1.25 \\
\hline Aug. 02, 2006 & 3.071 & 0.389 & 6.855 & 72.360 & 73.029 & 1.00 & 1.00 \\
\hline Aug. 04, 2006 & 3.071 & 0.399 & 6.687 & 68.657 & 69.710 & 1.00 & 1.00 \\
\hline Aug. 16, 2006 & 3.071 & 0.466 & 5.731 & 56.250 & 58.078 & 1.00 & 1.00 \\
\hline Aug. 22, 2006 & 3.071 & 0.320 & 8.333 & 129.249 & 130.919 & 1.00 & 1.00 \\
\hline
\end{tabular}



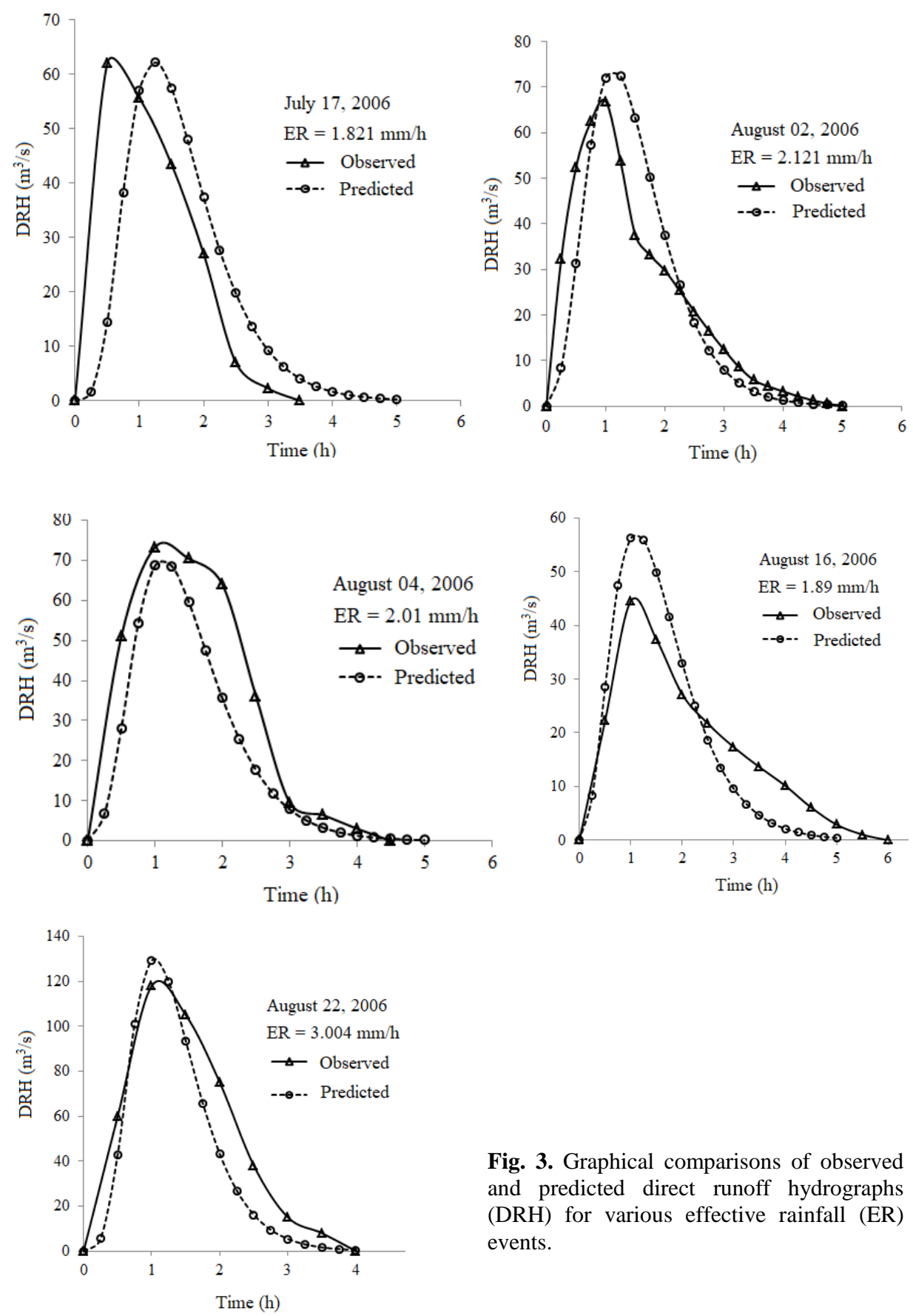

Fig. 3. Graphical comparisons of observed and predicted direct runoff hydrographs (DRH) for various effective rainfall (ER) events.

The quality of GIUH-Nash model-based runoff prediction depends on the accuracy of the estimation of its parameters. Visual comparison of observed to predicted values provides a quick assessment of model fit. The peak flow rates or volumes were evident from such a comparison. Moreover, this visual graphical comparison helped us to better understand the model capability and its sensitivity to changes in the Manning's coefficient. 
Accordingly, an optimal value of Manning's coefficient was identified through the process of visual inspection of the plots. Eventually, the comparison between the observed and predicted hydrographs (Fig. 3) revealed that predicted peaks were larger than observed peaks in three storm events, smaller in one storm event and nearly the same for the remaining one event. The time peaks of the predicted and observed peak runoffs were $1.0 \mathrm{~h}$ for three events, whereas $1.25 \mathrm{~h}$ for two events. The predicted runoffs has a time lag of 0.25 $\mathrm{h}$ (Table 2). The time base of both the modeled and observed hydrographs is fairly the same for all the events.

The statistical indices (Table 3) are computed using equations $12-18$. The minimum values of NSE and $S C$ are found to be 0.507 and 0.843 , respectively, indicating the adequacy of the GIUH-Nash model. In general, the EV and ETP don't show significant variation among the predicted and observed values. The negative values in $R E P$ and $E V$ indicate that the predicted peaks and volumes are more than the observed peaks and volumes, and time peaks of predicted are more than that of observed in ETP. RMSE seem to be slightly higher in some of the storm events.

Table 3. Statistical measures for GIUH-Nash model.

\begin{tabular}{|c|c|c|c|c|c|c|c|}
\hline Storm event & $R E P(\%)$ & $R M S E$ & $E V(\%)$ & $E T P$ & $M A E$ & $N S E$ & $S C$ \\
\hline Jul. 17, 2006 & -0.349 & 16.237 & 0.742 & 0.75 & 10.375 & 0.507 & 0.843 \\
\hline Aug. 02, 2006 & -8.226 & 10.904 & -0.372 & 0.25 & 7.122 & 0.740 & 0.856 \\
\hline Aug. 04, 2006 & 6.335 & 14.013 & 30.101 & 0.00 & 10.132 & 0.759 & 0.948 \\
\hline Aug. 16, 2006 & -26.164 & 7.163 & 0.659 & 0.00 & 5.949 & 0.722 & 0.942 \\
\hline Aug. 22, 2006 & -1.498 & 16.561 & 21.501 & -0.25 & 13.319 & 0.840 & 0.967 \\
\hline
\end{tabular}

\section{Conclusions}

The correct assessment of river flow is necessary to resolve a wide range of problems in the management and use of water resources, which are currently being solved using various types of modeling. DEM has recently become the main source of data for the characterization of rivers and river basins used in numerous hydrological models. As such, a $30 \mathrm{~m}$ resolution SRTM-DEM was used to generate the catchment physiographic and geomorphologic characteristics using QGIS. The drainage networks of the study area were created with threshold value intuitively chosen generating $4^{\text {th }}$ ordered stream networks. Accordingly, the stream ratios in which the outcomes of Nash parameters depend were determined graphically. Fortunately, the correlations between the stream order and the logtransformed parameters (stream number, mean stream length and mean stream area) were satisfactory for the generated drainage networks.

To evaluate the model performance five storm events and their corresponding singlepeaked hydrographs were selected. A visual comparison of observed values to predicted values of the direct runoff hydrographs as well as statistical indices showed reasonably acceptable performance of the GIUH-Nash model. Thus, it is concluded that the model could be used in areas where there is lack of reliable and sufficient rainfall and runoff data provided that the relationship, expressed in terms of the coefficient of determination, for the stream orders and log-transformed parameters is high. Nonetheless, catchments that have an outlet located near an upstream confluence of two major rivers may possibly give smaller values of higher order length which leads to lower coefficient of determination. Under these circumstances, it is preferable to look for other models that perform better than GIUH-Nash 
model. This is one of the critical points that must be considered seriously as it has major implications on the outputs of the GIUH-Nash model. Besides, Manning's coefficient happened to be the most sensitive parameter greatly affecting the overall performance of the GIUH-Nash model; hence, reasonable and appropriate value corresponding to the catchment area under consideration, must be identified before applying the model for runoff predictions.

Finally, in order to promote understanding on the use of effective hydrological models on one hand and avoid inefficient approaches on the other hand, additional studies should be undertaken using other surface runoff forecasting models in the catchment area in conjunction with available reference information systems. This would facilitate the adoption of appropriate management decisions that ultimately take into account the specific features of water management design in arid and semi-arid areas.

This work was financially supported by Ministry of Science and Higher Education of the Russian Federation (\#NSh-3492.2018.8).

\section{References}

1. L.K. Sherman, ENR. 108, 4 (1932)

2. K.J. Beven. Rainfall-runoff modelling: the primer (John Wiley and Sons, Chichester, 2012)

3. J.E. Nash. IAHS 45, 3 (1957)

4. B.C. Yen, K.T. Lee, J. Hydrol. Eng. 2, 1 (1997)

5. I. Rodriguez-Iturbe, J.B. Valdes, Water Resour. Res. 15, 6 (1979)

6. V.K. Gupta, E.C. Waymire, C.T. Wang, Water Resour. Res. 16, 5 (1980)

7. I. Rodriguez-Iturbe, M. Gonzalez-Sanabria, R.L. Bras. Water Resour. Res. 18, 4 (1982a)

8. R. Rosso, Water Resour. Res. 20, 7 (1984).

9. R.E. Horton, Geol. Soc. Am. Bull. 56 (1945).

10. F. Zakizadeh, H. Malekinezhad, Russ Meteorol. Hydro. 40, 12 (2015)

11. J.E. Nash, J.V. Sutcliffe, J. Hydrol. 10,3 (1970) 